\title{
Japanese Long-term Eldercare System Still Fails Women and the Poor: Who are Family Caregivers and What Do They Do?
}

\author{
Kamila Kolpashnikova, University of Oxford \\ Man Yee Kan, University of Oxford
}

\begin{abstract}
On the surface, an average day of caregivers is not considerably different from non-caregivers, but caregivers spend more time doing housework and less-doing work or enjoying leisure activities. Using the Japanese Time Use Survey, we perform cluster analysis and identify five patterns of daily time-use lifestyles of elder caregivers: (1) the leisurely weekend caregivers, (2) the multitaskers, (3) the sandwich caregivers, (4) the working poor caregivers, and (5) the agriculture/construction traveler caregivers. Our results show that the first three groups spend the most time on caregiving activities, but a larger proportion of sandwich caregivers report doing eldercare on the diary day. Care activities for sandwich caregivers are more likely to coincide with housework, which increases the volume of the total unpaid work significantly. The fourth type of daily time use patterns and their demographic profiles reveal that they are heavily overrepresented by the working poor, hence the choice of the name of the category. Even among other types, caregivers are more likely to live in households that have lower income than noncaregivers. Our results imply that caregivers face higher economic strain than non-caregivers, even among those caregivers who work. This applies particularly to women because the findings also indicate that women are more likely to be caregivers than men.
\end{abstract}

Keywords: elder care, Japanese elder caregivers, long-term care system, sandwich caregivers, sequence analysis

Although elder caregivers may enjoy emotional rewards from taking care of elderly parents (Folbre 2012, Silverstein and Giarrusso 2010), they hardly receive any economic benefits (Bianchi, Robinson and Milkie 2006, Wolf and Soldo 1994, Zuba and Schneider 2013). When 
caregiving is assumed to be the responsibility of specific populations more than others, it can accumulate substantial disadvantages among the caregiving populations, specifically women, who are traditionally expected to assume the role of primary caregivers. Moreover, negative consequences for well-being are more prevalent among women caregivers than among men because women accumulate a greater share of the disadvantages which come together with care provision (Bookman and Kimbrel 2011).

The contribution of the present paper is twofold. First, we explore whether the long-term care system alleviated the position of the segments of the population that it was aimed at, particularly the status of women. The findings of this paper will have policy implications that will need to be addressed in Japan and perhaps could work as a lesson for other states and regimes that plan to implement similar policies. The second contribution of the present study is that no research to this day analysed the time use patterns in the everyday lifestyles of elder caregivers in detail, using time-use diaries. Recently, Grapsa and Posel (2016) used sequence and cluster analyses methods to describe time use patterns of the elderly, but no study yet focused on the time use patterns of the elder caregivers. Our paper will be the first one to do so, using Japan as a case study. We chose Japan as the country with one of the highest proportions of the ageing population and arguably one of the best social programs for eldercare. Thus, Japan is ranked \#8 in the eldercare system globally according to the Global AgeWatch Index 2015 (HelpAge International 2014).

Overall, this study identifies the time use of primary caregivers, as well as described main categories of caregivers based on the daily lifestyles. The main objectives of the present paper, therefore, are to explore: (1) the types of caregivers based on their daily time use (lifestyle) patterns; (2) the demographic profiles of caregivers in contrast to the general profile of noncaregivers, including their socioeconomic status and occupation. To foreshadow our results, we find that even within the contexts with progressive eldercare policies like in Japan, women and the working poor are disproportionately disadvantaged in making the most of such systems.

\section{Theoretical Background}

Eldercare remains a gendered activity. Compared to the division of labour in paid and unpaid work, traditional expectations persist in elder care, where we see fewer changes in women's position (Grigoryeva 2017, Levitsky 2014). It is often taken for granted that eldercare becomes 
wives' and daughters' responsibility in countries with less developed social systems, but as we will show in this paper, it is also true in states with more progressive social support systems for the elderly.

\section{Contextual Background: Eldercare in Japan and the Long-term Care Insurance System}

The elderly in Japan benefit from a better support system from the government than in the US or the UK such as universal healthcare and long-term care insurance system for those above 65 (all adults are enrolled at 40). However, due to the rapid increase in the elderly population, the Japanese government admits to facing financial strains as to the implementation of the system. It takes steps to share eldercare obligations with local communities and the families of the elderly. This course of the governmental policy is understandable considering the precipitous increase in the population of the elderly in Japan. The elderly represented about $20 \%$ of the population in 2005 and rose to $27 \%$ in 2015 . Moreover, they are projected to reach almost $40 \%$ of the population in 2050 (Ato and Tsuya 2018).

Even though Japan has a progressive system of local and federal support for the elderly, most elder care in Japan remains on the shoulders of family members. Morikawa (2018) argues that a part of the reason is that the policy implementation could not reach the universal level due to an unexpectedly high level of financial strain on the country's budget. Because of the unanticipated spurt of eldercare demand, when the number of enrollments doubled within the first five years since the implementation of the long-term care system, the government found itself forced to revise the policy from its initial focus on public provision (社会化 'shakaika' socialism) back to local (地域化 'chiikika' regionalism), and de facto family provision (再家族化 'zaikazokuka' re-familism).

Changes in the law that were introduced in 2005, therefore, stymied the increase in enrollment as

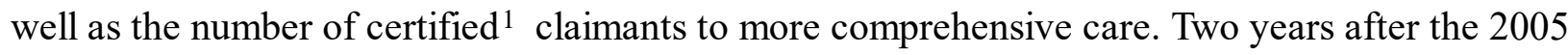
revision, $60 \%$ of the elderly co-resided with family members. Among elder care recipients, 25\% of the total were taken care of by their spouses, $17.9 \%$ - by their children, and $14.3 \%$ - by

\footnotetext{
1 The claimants to the benefits need to go through the assessment procedures, upon which they are granted a certificate specifying the tier of their elder care needs.
} 
spouses of their children (Morikawa 2018). Although the numbers of family care recipients decreased in the first five years on the long-term insurance system implementation, the trend stalled on the same level as reported above since 2007. One exception was for those who received care from their children's spouses.

The original purpose of the long-term care insurance system was to move from the family caregivers model to public caregiving system. Ideally, such a system should have alleviated the burden on families, particularly on women. However, Morikawa (2018) insists that these ideals were revised and abandoned, facing harsh realities of budgetary constraints. The burden on children and spouse caregivers continues to remain unaffected by the long-term care system.

Nonetheless, there is one category of caregivers for whom the system has been more effective in alleviating the eldercare burden. The trends show that the long-term care insurance system reduced the proportion of in-laws (the spouses of children) as caregivers. Since the introduction of universal long-term care insurance system in 2000, the share of in-law caregivers decreased from $22.5 \%$ (on par with own-child caregivers) in 2001 to $11.2 \%$ (almost twice less than ownchild caregivers) in 2013. On the other hand, the proportion of paid caregivers surged from $9.3 \%$ to $14.8 \%$ in the same period, whereas all other categories of caregivers remained level (Morikawa 2018).

\section{What are the Common Lifestyles of Caregivers?}

The previous research focused on family structures rather than the lifestyles of caregivers (for the full review see Silverstein and Giarrusso (2010)). Little is known in quantitative research about how the time use patterns of caregivers look like and whether there are commonalities in what they do on regular days as a result of their shared experiences and responsibilities as elder caregivers except from the qualitative research (Aounet al. 2015, Tayet al. 2016, Weisser, Bristowe and Jackson 2015) and the research of physical and mental health (Boltzet al. 2015, Houet al. 2014).

One distinct category of caregivers that have been given much attention in the previous research is the sandwich caregivers (Henretta, Grundy and Harris 2001, Suh 2016, Yamashita and Soma 2015). Sandwich caregivers are providers of both elderly and childcare. It is usually women in their 30s and 40s. Fukuda (2018) found that among Japanese sandwich caregivers, the proportion of eldercare rose concurrently with childcare. These two care activities, therefore, were not in a 
time-constraint/role-conflict relationship but actually increased in tandem. Thus, the role conflict for sandwich caregivers is not between the roles of a child (toward elderly parents) and a parent (toward dependent children) but between caregiving (being a family member) and work activities (being an employee).

The Japanese studies of sandwich caregivers made the above contribution to the previous role conflict theory (Zuba and Schneider 2013). The role conflict frontline in the eldercare outlines the border of the family unit and is not situated within the family. This exponential pattern of association between care activities must create profound consequences for the lifestyles of sandwich caregivers. These consequences might involve drastic changes to work schedules, reduction of paid work time or exit from the workforce, among other things (Bianchi, Robinson and Milkie 2006, Wolf and Soldo 1994, Zuba and Schneider 2013).

For those caregivers that can still afford to work, it is reasonable to expect some weekday and weekend differences in partaken activities. The patterns of most weekend activities were asserted to be unlike those on weekdays (Hertoget al. 2018, Hook 2017, Ruppanner and Treas 2015). For instance, Ruppanner and Treas (2015) showed that employment on the weekend benefited men in terms of reducing their housework and care activities but did not alleviate women's unpaid work. In care activities, therefore, we might observe differences between weekdays and weekends, as well as gender differences in both weekday and weekend activities. Hook (2017) found that women are more likely to engage in gender-asserting activities on weekends, such as participating in more traditionally feminine activities like housework and care activities.

Therefore, based on the literature on the expected variation in lifestyles among elder caregivers, we expect at least five distinct categories of lifestyles: women on weekdays and weekends, men on weekdays and weekends, as well as sandwich caregivers as a distinct category. The actual classification, however, will depend on what the cluster analysis of time use patterns will reveal.

\section{How Different Caregivers are from Non-caregivers?}

In housework, studies showed, again and again, that gender trumps money (Bittmanet al. 2003, Kolpashnikova 2018) but in elder care, recent research reveals that gender is often trumped not by money but by kin relations and obligations (Grigoryeva 2017, Henz 2010, Szinovacz and Davey 2008). Children provide more elder care to their own parents, but not to the parents of their spouses (Henz 2010, Szinovacz and Davey 2008). In Japan, the situation with elder care is 
more and more similar to the one in the West. Although the share of own-child caregivers remained on the same level from 2001 to 2013, the provision of elder care by in-laws (the spouses of own children) decreased by half in the same period (Morikawa 2018).

The social obligation of filial care is often reported not to discriminate by gender in western societies (Henz 2010, Szinovacz and Davey 2008). Nevertheless, the recent research shows that no 'gender difference' in providing eldercare between spouses actually conceals the gender disparity at the aggregate level. The mechanism resulting in such paradox lies in the division of eldercare between siblings (Grigoryeva 2017) when the outcome more often than not is gendered and discriminates against sisters. This means that there are gender differences in eldercare on the aggregate level as a result of the sibling differentials. Overall, other studies showed that women, married sisters, and single women alike, take on more care work than men (Bianchiet al. 2000, Moen, Robison and Fields 1994, Nichols and Junk 1997).

There are a few theories that propose the explanation of the uneven distribution of eldercare responsibilities. The 'doing gender' perspective provides the first explanation. According to this perspective, because care activities are 'quintessentially' feminine, more women than men are expected to perform them (Cancian and Oliker 2000, England 2005). On the other hand, men are free to choose whether they want or do not want to participate in care activities (Gerstel 2000). Considering the aggregate patterns, many choose to provide financial substitutes of care or outsource care activities rather than contribute their own time to care activities. Moreover, there are disproportionate expectations placed on women and men regarding care activities. Women are more likely to be held responsible if they delegate care activities to third persons because they are viewed as breaking gender norms and expectations.

Therefore, we expect to see differences in gender proportions between caregivers and noncaregivers, where women are more likely to be caregivers than men [H1].

Second, the time availability approach is also relevant to eldercare provision. Eldercare is a type of unpaid labour, therefore, most frameworks that apply to housework apply to elder care as well. This includes the time availability and other resource-based frameworks, such as absolute and relative resources approaches (Bianchi, Robinson and Milkie 2006, Fukuda 2018, Wolf and Soldo 1994, Zuba and Schneider 2013). Because of their increased responsibilities at home, caregivers are more likely to experience work-family conflict. Because work responsibilities put 
additional demands on their time, which might be incompatible with their caregiving responsibilities, there might be differences between non-caregivers and caregivers in paid work time. Moreover, more often than not, when it comes to the work-family conflict, the previous research has shown that women caregivers are more likely to decide in favour of family responsibilities (Bookman and Kimbrel 2011).

The research has also shown that the time conflicts are even more likely when the role of a caregiver is doubled with childcare among sandwich caregivers (Fukuda 2018, Suh 2016). Therefore, we can infer that sandwich caregivers are even more likely to quit their jobs and devote their lives to household activities.

Therefore, we expect that caregivers will spend less time on paid work than non-caregivers, especially sandwich caregivers [H2].

Third, the resource-based approaches might also explain the differences between elder caregivers and non-caregivers. Unlike housework, care is not a lopsidedly unpleasant task because it provides a plethora of emotional rewards (Folbre 2012, Silverstein and Giarrusso 2010). Because of these emotional rewards, having more resources would not always equate with lower care obligations. However, higher levels of household and individual resources, especially among working women and men, would allow households to provide financial support in lieu of physical care, or provide with more opportunities to outsource it to paid care (Couch, Daly and Wolf 1999). Thus, we expect some effect of resources on being an elder caregiver:

Therefore, we can expect that, on average, caregivers will have lower levels of income than noncaregivers, who can afford to outsource care activities [H3].

\section{Methods}

\section{Data and Sample}

In this paper, we employ anonymised microfiles of the 2006 Survey on Time Use and Leisure Activities (STULA) (Statistics Bureau 2016). STULA collects time diaries for two consecutive days from a representative sample from the Japanese population. The survey sample uses a twostage stratified sampling method. The primary sampling unit is the enumeration district (ED) of 
the Population Census, and the secondary unit is households. In 47 Japanese prefectures, a total of 6,902 EDs were selected. All household members ten years of age and above were asked to complete the survey. Foreigners living in Japan were also included in the survey. The initial microfile data contained 272,861 observations. The first step we took for the present study, we restricted the sample to the first diary day only. Because the STULA collects the data for the two consecutive days, we believe that the second-day reporting can be contaminated with the reports or inaccurate reports due to filling in the STULA questionnaire on the diary day. The total sample for the comparison in the present study employed 136,596 observations of at-home careproviders and non-caregivers alike on their first diary day. In the analysis of sequences for the caregivers, we limited the sample for those who reported providing the elder care at home $(3,555$ observations, $2.6 \%$ of the respondents on the first diary day). We restricted the sample to those who provide elder care at home to focus on family caregiving.

Although 2006 STULA is an old data, the trends among own-child caregivers have been shown to have remained on a similar level since the 2005 revisions of the long-term care insurance system (Morikawa 2018). Therefore, we expect to see the patterns established in the 2006 STULA in the later waves as well and conclude that the 2006 data might be representative of the post-revision era of the long-term care system.

The restricted sample of the caregivers on the first diary day allowed us to preserve the computational speed as well as the visibility of results (when plotted together, a larger number of sequences tend to blur). However, we ran the robustness check for the clustering for the second day as well. The results for the second diary day were similar to those reported here. In Japan, most elder care is provided by those who co-reside with the elderly, their family members. Thus, the co-residing family care comprised $66.1 \%$ of all caregivers in 2004 and slowly declined to 61.6\% in 2013 (Morikawa 2018). The change is mostly attributed to the decrease in caregiving from in-laws and a commensurate increase in the use of paid care facilities (Morikawa 2018). In 2006 STULA elder caregivers sample, co-residing caregivers comprised $64.08 \%$ of all elder caregivers (7102 out of 11083 observations on both diary days). There are 3555 sequences in the STULA dataset of at-home elder caregivers, all but two are unique sequences (this means that in the sample there are only two identical sequences), but, considering a large number of steps (96), 
it is not surprising to have only two unique sequences.

\section{Dependent and Independent Variables}

The main dependent variable that is later used for the multinomial regression analysis is the categories of at-home elder care-providers identified from the cluster analysis of sequences, employing the optimal matching technique. We also included an additional zero category, which represents the non-caregivers of elder care, not included in the cluster analysis. In models, this category of non-caregivers is used as the referent.

For the logistic regression models, we add a number of independent variables to our models. The education variable is measured in years spent in school. We also control for the time spent on paid work and whether the respondent is employed ( $1=$ 'employed'; $0=$ 'not employed'). Paid work variable measures how many minutes the respondent spent on paid work on the diary day.

Control variables also include household income, which measured in ten thousand Japanese yen. The age is measured in years. Household size measures the number of all members in a household. We also control for the presence of children in the household. There are dummy variables controlling for whether the respondent is a woman ( $1=$ 'woman'; $0=$ 'man'), owns the home where they live $(1=$ 'owns the home'; $0=$ 'does not own the home'), or is married $(1=$ 'married'; $0=$ 'otherwise'). All the above demographic variables help us create a better profile for the characteristics of people who embody certain care-provider lifestyles and demographics.

Since there are usually considerable differences in diaries depending on the day of the week when the diary was collected, we also control for whether the diary day was completed for a weekday or the weekend ( $1=$ 'weekday', $0=$ 'Saturday or Sunday'). Another control variable is whether the respondent resides in an urban area ( $1=$ 'major metropolitan area', $0=$ 'not urban').

In the tempograms based on the cluster analysis results, we used childcare and housework 
activities as additional factors, which might influence the lifestyles and the amount of unpaid work of caregivers. The eldercare responsibilities often require sacrificing time that would be otherwise spent on the labour market or in building relationships with other people. Moreover, elder care can also coincide with other activities that are part of everyday activities and might not always be categorised by respondents as elder care. These activities mainly refer to housework such as cooking for the elderly (as well as for the family), shopping, and cleaning. Morikawa (2018) summarises that family caregivers do most such housework tasks. Thus, in 2004, 78.8\% of elder care recipients asked solely family caregivers to do their laundry, and $65.5 \%$ of them were dependent on their families for food preparation. The only tasks that were reported not to be done by family caregivers in the majority of cases were washing hair (洗髪) $-39.9 \%$ and help with bathing (入浴介助) $-38.6 \%$ (Morikawa 2018). Thus, elder care seems to be outsourced mostly when the old age curbs the physical ability of people and they require the help of professional caregivers. Therefore, we decided that it is crucial to report the episodes of elder care in tandem with housework and childcare.

For the additional exploration of caregiver occupations, we also used a variable that categorises the occupation of respondents. There are 15 main harmonized occupational categories: (trades) technician, (trades) instructor, (trades) other trades occupation, managerial occupation, office worker, sales representative, (services) care support service worker, (services) insurance worker, (services) other service worker, agriculture worker, transport worker, (industry) worker, (industry) construction worker, (industry) blue-collar worker, and other unclassifiable jobs.

\section{Models}

We use sequence analysis (Stata SQ package) to investigate the lifestyles and characteristics of care-providers in Japan. We ordered reported activities throughout the day into sequences; each step represented 15-minute interval, totalling 96 steps. Each sequence is then compared to other sequences using the optimal matching technique (the Needleman-Wunsch algorithm) (Abbott 1995, Abbott and Tsay 2000, Sankoff and Kruskal 1983).

Based on the dissimilarity matrix obtained from the optimal matching analysis, we performed the 
cluster analysis and clustered the activity sequences into five main groups, based on the main branches of the resulting clustering dendrogram. The main logic of dividing into the possible five groups was outlined above: we anticipated differences by weekday among women and men, as well as a distinct pattern for sandwich caregivers. Usually, individual activities vary by weekend and weekday. Therefore we envisioned that the differences would arise on weekend and weekday sequences. On the other hand, the lifestyles of women and men are also quite different, so we also expected the division of sequence patterns by gender. Thus we expected to have four main categories. We decided to include the fifth conceptual category, in case the sandwich caregivers pattern did not fit into any of the four conceptual categories. The results, discussed below, revealed slightly different categories of caregivers than anticipated theoretically.

There are 20 categories of activities in the original time diaries, which we employed for the optimal matching analysis. For tempograms, however, we reduced the number of activities to 11: sleep, personal care, eating, work, leisure, TV watching, housework, care work, childcare, travel, and other activities. Each step within sequences represents a 15-minute interval, totalling 96 such intervals in 24 hours day. Each sequence starts at 00:00 am and ends at 11:59 pm.

In addition, to analyse which demographic characteristics are associated with being clustered into a certain group of caregivers, we performed multinomial logistic regression against demographic factors. The reference category was the non-caregivers. Each category of careproviders was therefore compared to the non-caregivers. We report relative risk ratios in Table 2 . We also report the descriptive results for the proportional representation of care-providers and non-caregivers by 15 different occupations.

\section{Results and Discussions}

First, we compared the overall patterns of daily activities among caregivers and non-caregivers, which are summarized in Figures 1 and 2. On the surface, there are almost no apparent differences between the two subsamples. However, higher proportions of the elder caregivers spend time on housework activities and fewer-on paid work on an average day (see Table 1). We found that during the daytime (between 9 am and $6 \mathrm{pm}$ ), many caregivers like non-caregivers spent time on work, housework, leisurely activities, or watched TV and other media. The tempograms also show that care activities in the entire sample of caregivers are evenly distributed throughout the day, with no visible spikes (see Figure 1). Majority of the sample also 
sleeps and eats meals at the usual times.
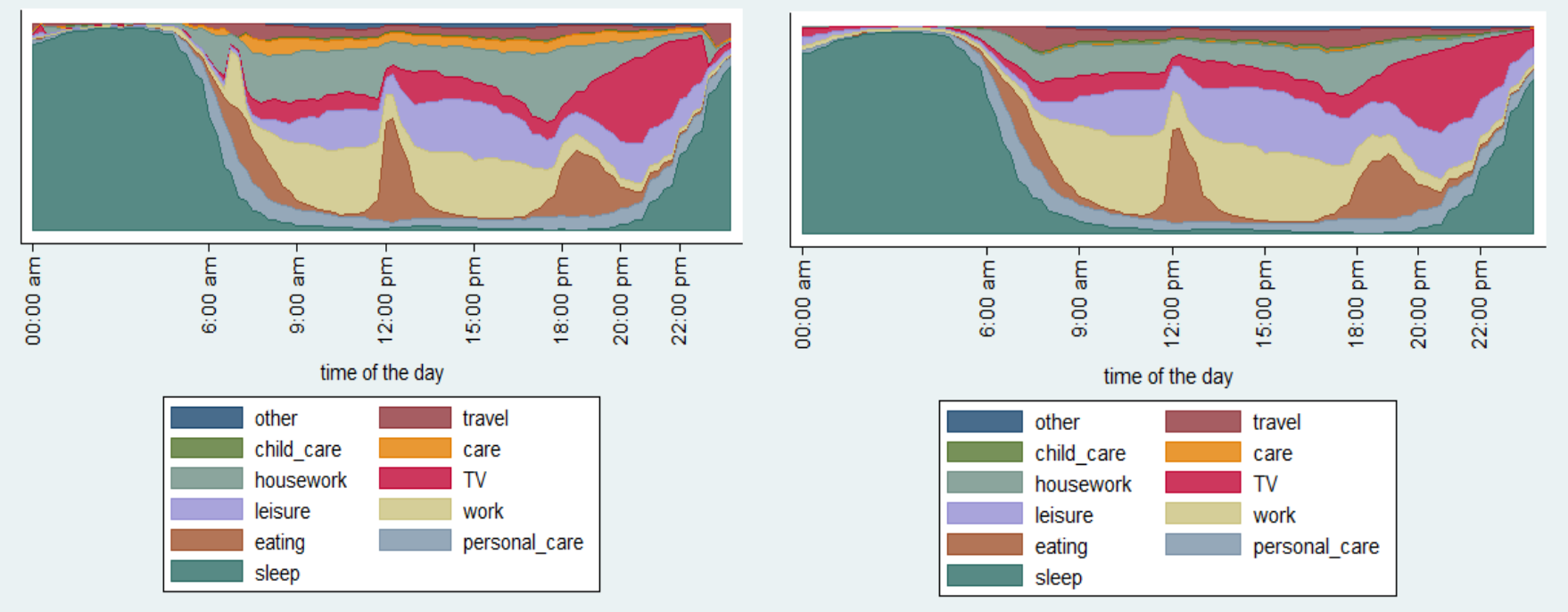

Figure 1 Daily Activity Tempograms for Elder caregivers (left) and Non-caregivers (right)

Among the self-reported caregivers, the majority (62.95\%) did not report spending any time on care activities on the diary day. This indicates that most caregivers do not provide care on a daily basis or perhaps, their care activities coincide with normal daily activities, particularly with housework. It is likely that these housework activities were not viewed by the respondents as eldercare activities and thus were not coded as such. However, considering the significant differences in the amount of housework done between caregivers and non-caregivers, we can infer that in general, the caregiver status increases housework responsibilities.

\section{Cluster Analysis Results}

We employed cluster analysis on the sequences of self-reported caregivers, identifying five main clusters. These clusters or categories of sequences represent different types of the daily lifestyles of Japanese caregivers. Contrary to our expectations, weekend activities for all caregivers comprised only one of the hypothesised clusters. No gender differences were observed in the weekend activities among caregivers. However, as we expected, sandwich caregivers' daily 
lifestyle comprised a distinct cluster. The rest three clusters consisted of the varying patterns of working caregivers. We have named them based on the predominant reported activities: (1) leisurely (which also coincided with the weekend pattern for caregivers), (2) multitaskers, (3) sandwich caregivers, (4) workers, and (5) travellers. Most respondents fell into the leisurely cluster (26.05\%), the multitaskers (23.66\%), and the travellers (29.93\%). Group 4 ('workers') had the lowest number of observations (4.5\%), and the sandwich group was in between $(15.86 \%)$. See Appendix A for the tempogram outputs for all groups.

Comparing daily lifestyle categories, we note some differences among caregivers by how they involve in care activities. Figure 2 summarises both adult and childcare activity episodes across five clustered groups. The $\mathrm{x}$-axis in all sequence plots represents the hours and minutes of the diary day from 12 am to $11: 59 \mathrm{pm}$. Although many respondents do not report doing any care activity on the diary day, especially among 'the working poor caregivers', we can spot differences among the five identified clusters.

1

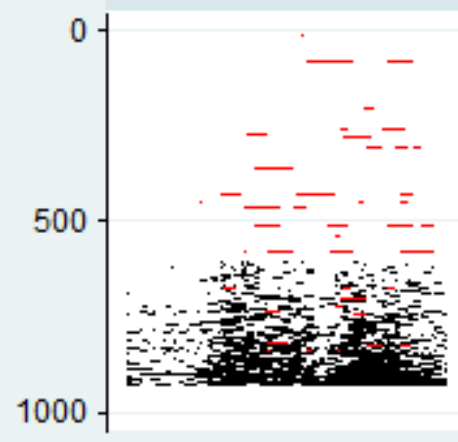

4

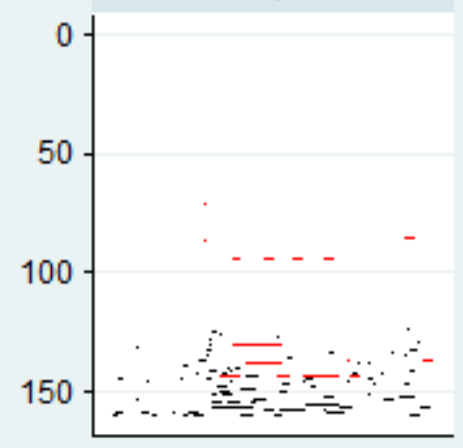

2

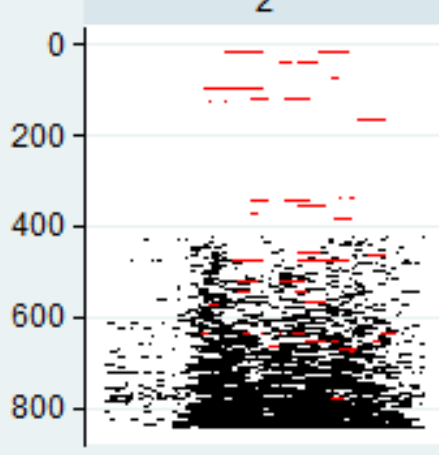

5

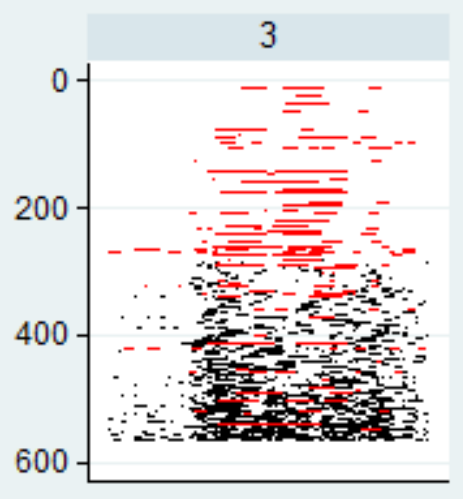

600 
The multitaskers provide the most intensive eldercare, a large proportion of whom spend long hours providing elder care, followed by the leisurely and sandwich caregivers. The multitaskers report, on average, 6.5 episodes of elder care (approximately 1 hour and 40 minutes a day). However, it is essential to note that among sandwich caregivers, a higher percentage report doing eldercare on the diary day, even though the episodes are overall shorter than among the multitaskers and leisurely.

Figure 2 also reveals another pattern: caregiving often occurs in the mornings and the evenings, forming two modal groups in those two periods for most groups, except among the 'workers', where it has a very sporadic and unidentifiable character.

We also notice that the workers (group 4) do not provide much care at all, compared to other groups. The average number of reported episodes (each lasts 15 minutes) is about 1 for the group, whereas groups 1-3 report around 3 to 6 episodes of elder care (45 minutes to 1.5 hours). Group tempograms (Appendix A) also reveal that Group 4 spends the most time on paid work activities. In fact, they often work in the evenings as well (see Appendix A). They also spend much time on travel, perhaps from shift to shift in their part-time jobs (such as restaurants and retail shops).

We added another dimension in Figure 3-housework (including shopping). We note that the sandwich caregivers are more likely to spend more time on housework than other groups. The analysis of the length of episodes also revealed that the average number of episodes of housework for the sandwich caregivers group (Group 3) was approximately 28 , which amounts to about 7 hours on an average day. Therefore, care activities for the sandwich caregivers are more likely to coincide with housework and increase care-related activities many times.

Table 2, which summarizes demographic profiles for the five categories of caregivers, shows that although the 'workers' (Group 4) spend considerably more time on paid work (575 min on an 
average day) than the average in the total sample (191 min), their household income is similar to the average (5.38 mln yen annually versus 5.41). Therefore, this category might be represented more by the working poor.

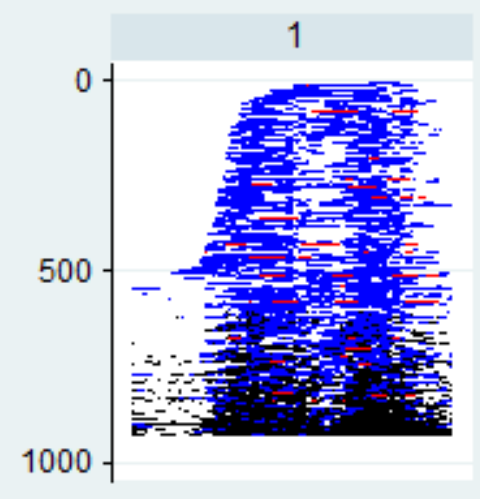

4

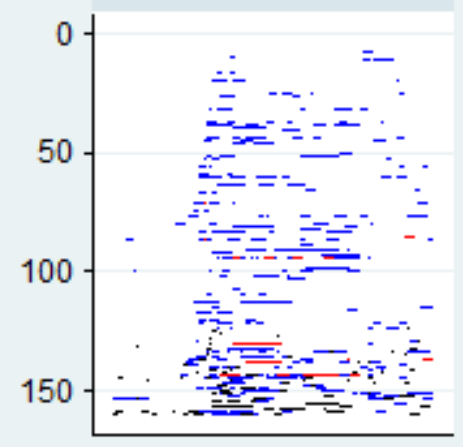

Graphs by gr
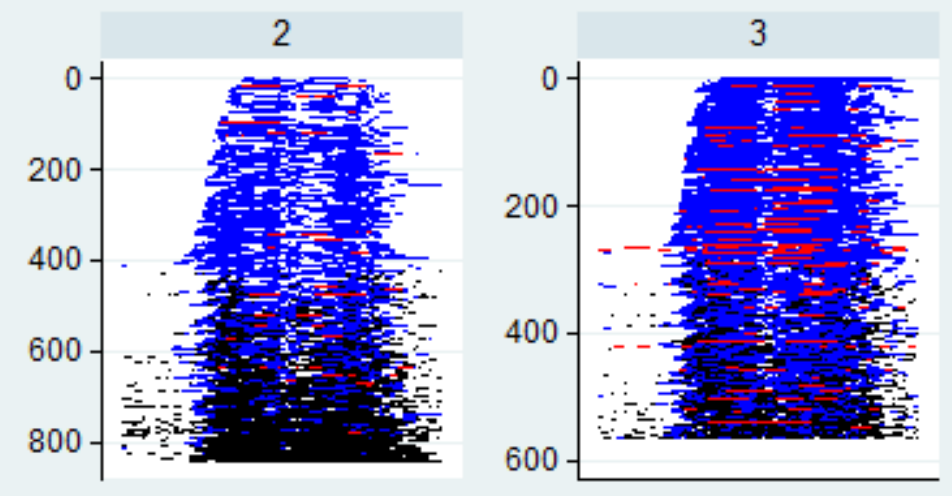

5

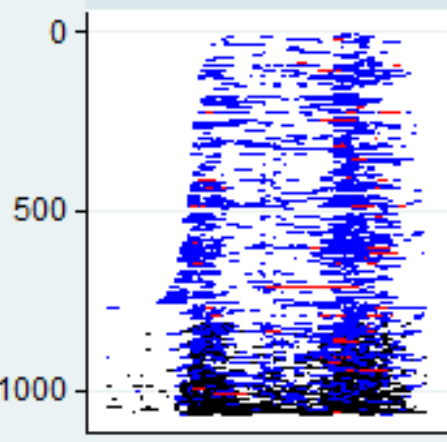

Figure 3 Activities by Groups. Black = episodes of adult care, Red $=$ episodes of child care, Blue $=$ Housework

Table 1. Mean (SD) of Main Variables

\begin{tabular}{lccccc}
\hline & $\begin{array}{c}\text { Household } \\
\text { Size }\end{array}$ & Income & Education & Age & Children \\
\hline Non-caregivers & 3.193 & 541.018 & 11.686 & 48.308 & 0.301 \\
Group 1 & $(1.403)$ & $(360.468)$ & $(2.806)$ & $(20.469)$ & $(0.459)$ \\
& 3.629 & 573.758 & 11.739 & 53.589 & 0.235 \\
Group 2 & $(1.390)$ & $(399.794)$ & $(2.842)$ & $(18.518)$ & $(0.424)$ \\
& 3.246 & 436.029 & 10.982 & 66.746 & 0.169 \\
Group 3 & $(1.404)$ & $(355.088)$ & $(2.264)$ & $(14.312)$ & $(0.375)$ \\
& 3.401 & 526.418 & 11.765 & 60.450 & 0.332 \\
Group 4 & $(1.272)$ & $(370.184)$ & $(1.999)$ & $(11.988)$ & $(0.471)$ \\
& 3.719 & 538.125 & 12.509 & 49.594 & 0.294 \\
Group 5 & $(1.275)$ & $(344.612)$ & $(2.187)$ & $(12.626)$ & $(0.457)$ \\
& 3.831 & 563.675 & 12.012 & 55.426 & 0.320
\end{tabular}




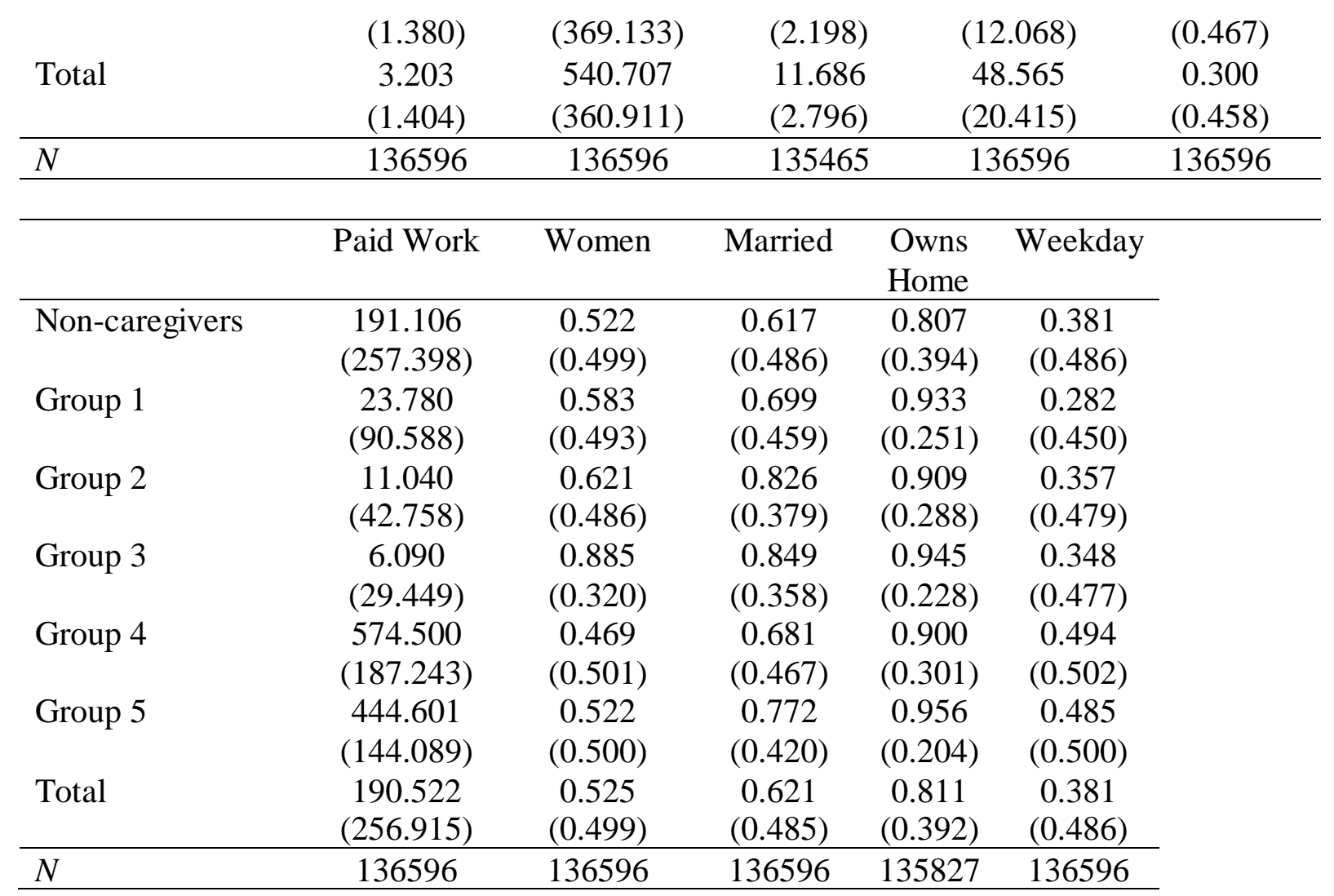

\section{Model Outputs}

Table 2 summarises the results of the relative risk ratios from the multinomial logistic regression model testing various demographic factors in their association with the probability whether the respondent could be in one of the caregiver categories over being a non-provider.

There are a few findings that would be expected with the demographic in question. For instance, Table 2 results show that for all categories, caregivers are likely to be older than non-caregivers. Caregivers are also significantly more likely to be married compared to non-caregivers, although this only refers to the first three groups and not for the workers (Group 3) and travellers (Group 4) categories, where the results show that they are more likely to be married than non-caregivers, as well, but the results are not on the significant level. Caregivers are more likely to live in bigger households than non-caregivers, one of the reasons being the co-resident elderly.

Other results are not as apparent. For instance, all groups except multitaskers are significantly more likely to have higher levels of education than non-caregivers. Table 1 confirms that, on average, multitaskers have a lower level of education than non-caregivers and other categories of 
caregivers. On the other hand, and perhaps most importantly, all caregiver groups are significantly more likely to live in hou seholds that have lower income than non-caregivers. The implication is that caregivers face higher economic strain than non-caregivers, even among those caregivers who work. These results indicate that although Japan does a tremendous job in providing care for its elderly, it is still cannot protect the economic consequences concomitant with the eldercare for the majority of the Japanese family caregivers.

Table 2. Multinomial Logistic Regression Models Outputs (Relative Risk Ratios), Noncaregivers as Reference Category

\begin{tabular}{|c|c|c|c|c|c|}
\hline & $\begin{array}{c}(1) \\
\text { Group } 1 \\
\text { Leisurely }\end{array}$ & $\begin{array}{c}(2) \\
\text { Group } 2 \\
\text { Multitaskers }\end{array}$ & $\begin{array}{c}(3) \\
\text { Group } 3 \\
\text { Sandwich } \\
\end{array}$ & $\begin{array}{c}\text { (4) } \\
\text { Group } 4 \\
\text { Workers } \\
\end{array}$ & $\begin{array}{c}(5) \\
\text { Group } \\
\text { Travellers } \\
\end{array}$ \\
\hline Household Income & $\begin{array}{c}0.616 * * * \\
(0.111)\end{array}$ & $\begin{array}{c}0.306 * * * \\
(0.075)\end{array}$ & $\begin{array}{c}0.324 * * * \\
(0.072)\end{array}$ & $\begin{array}{c}0.346^{* * * *} \\
(0.109)\end{array}$ & $\begin{array}{c}0.593 * * * \\
(0.086)\end{array}$ \\
\hline Education & $\begin{array}{l}1.062 * * \\
(0.026)\end{array}$ & $\begin{array}{c}1.004 \\
(0.030)\end{array}$ & $\begin{array}{c}1.091 * * * \\
(0.037)\end{array}$ & $\begin{array}{l}1.091^{*} \\
(0.050)\end{array}$ & $\begin{array}{c}1.086^{* * * *} \\
(0.030)\end{array}$ \\
\hline Age & $\begin{array}{c}1.007 * * * \\
(0.002)\end{array}$ & $\begin{array}{c}1.051 * * * \\
(0.004)\end{array}$ & $\begin{array}{c}1.031 * * * \\
(0.003)\end{array}$ & $\begin{array}{c}1.036 * * * \\
(0.009)\end{array}$ & $\begin{array}{c}1.044 * * * \\
(0.004)\end{array}$ \\
\hline Children = 1 & $\begin{array}{c}0.464 * * * \\
(0.064)\end{array}$ & $\begin{array}{c}0.585 * * * \\
(0.090)\end{array}$ & $\begin{array}{c}0.938 \\
(0.157)\end{array}$ & $\begin{array}{c}0.759 \\
(0.235)\end{array}$ & $\begin{array}{c}0.468 * * * \\
(0.071)\end{array}$ \\
\hline Household Size & $\begin{array}{c}1.371 * * * \\
(0.047)\end{array}$ & $\begin{array}{c}1.288 * * * \\
(0.044)\end{array}$ & $\begin{array}{c}1.443 * * * \\
(0.070)\end{array}$ & $\begin{array}{c}1.501 * * * \\
(0.083)\end{array}$ & $\begin{array}{c}1.459 * * * \\
(0.057)\end{array}$ \\
\hline Paid Work Time & $\begin{array}{c}0.994 * * * \\
(0.001)\end{array}$ & $\begin{array}{c}0.992 * * * \\
(0.001)\end{array}$ & $\begin{array}{c}0.989 * * * \\
(0.001)\end{array}$ & $\begin{array}{c}1.006 * * * \\
(0.000)\end{array}$ & $\begin{array}{c}1.004 * * * \\
(0.000)\end{array}$ \\
\hline Women $=1$ & $\begin{array}{c}0.882 \\
(0.107)\end{array}$ & $\begin{array}{c}1.093 \\
(0.140)\end{array}$ & $\begin{array}{c}6.159 * * * \\
(1.216)\end{array}$ & $\begin{array}{c}3.246 * * * \\
(0.936)\end{array}$ & $\begin{array}{c}2.148 * * * \\
(0.279)\end{array}$ \\
\hline Married $=1$ & $\begin{array}{c}1.496 * * * \\
(0.208)\end{array}$ & $\begin{array}{c}4.247 * * * \\
(0.753)\end{array}$ & $\begin{array}{c}3.438 * * * \\
(0.889)\end{array}$ & $\begin{array}{c}1.099 \\
(0.342)\end{array}$ & $\begin{array}{c}1.290 \\
(0.206)\end{array}$ \\
\hline Owns Home & $\begin{array}{c}1.416 \\
(0.333)\end{array}$ & $\begin{array}{c}0.897 \\
(0.201)\end{array}$ & $\begin{array}{c}4.652 * * * \\
(1.220)\end{array}$ & $\begin{array}{c}1.779 \\
(0.683)\end{array}$ & $\begin{array}{c}1.823 * * \\
(0.442)\end{array}$ \\
\hline Weekday & $\begin{array}{l}0.836^{*} \\
(0.086)\end{array}$ & $\begin{array}{l}1.144 \\
(0.115)\end{array}$ & $\begin{array}{l}1.252^{*} \\
(0.148)\end{array}$ & $\begin{array}{l}0.688^{*} \\
(0.151)\end{array}$ & $\begin{array}{l}1.185^{*} \\
(0.105)\end{array}$ \\
\hline Constant & $\begin{array}{c}0.001 * * * \\
(0.001)\end{array}$ & $\begin{array}{c}0.000 * * * \\
(0.000)\end{array}$ & $\begin{array}{c}0.000 * * * \\
(0.000)\end{array}$ & $\begin{array}{c}0.000 * * * \\
(0.000)\end{array}$ & $\begin{array}{c}0.000 * * * \\
(0.000)\end{array}$ \\
\hline $\begin{array}{l}\text { Observations } \\
\text { Pseudo R-squared }\end{array}$ & $\begin{array}{c}134,721 \\
0.149\end{array}$ & & & & \\
\hline
\end{tabular}

Robust standard errors in parentheses. $* * * \mathrm{p}<0.01, * * \mathrm{p}<0.05, * \mathrm{p}<0.1$ 
Leisurely caregivers are less likely to report to have children than non-caregivers. They are also less likely to spend as much time on work as non-caregivers. However, because the leisurely care-providers are more likely to report this daily lifestyle on a weekend day rather than on a weekday, we can infer that this 'leisurely' cluster mostly refers to caregivers' daily lifestyle on weekends. The 'leisurely' weekend caregivers are as likely to be women or men as in the noncaregivers category. Thus, this is the only category of caregivers that does not discriminate by gender. This finding implies that the weekend activities of caregivers do not differ depending on caregivers' gender. Table 1 confirms that the differences between non-caregivers and leisurely caregivers in gender proportions are minuscule. Fifty-eight per cent of the leisurely careproviders are women, whereas it is $52 \%$ for non-caregivers. Because this is the only category where men are as likely to belong to as women, the results show, therefore, that Japanese men caregivers mostly provide care on weekends because no other cluster of caregivers was identified where the gender composition would be in favour of men.

\section{Multitasker Care-Providers}

Similar to the 'leisurely' care-providers, the multitaskers are less likely to have children or work as long hours as the non-caregivers. This category is more likely to have a higher proportion of women than in the non-provider category. However, the estimates are not on a statistically significant level (see Table 2, rrr=1.093, p>.05). Unlike the 'leisurely' weekend care-providers, this category is more likely to report this type of daily lifestyle on weekdays than on the weekends, when controlled for other variables. Table 2 also shows that the lowest level of annual household income is for women and men in this category. The multitaskers also represent the category with the lowest level of average education. Therefore, the lower levels of income might also be connected to their lower educational level, rather than the status of caregivers per se.

\section{Sandwich Caregivers}

The sandwich caregiver category is more likely to be represented by women both compared to non-caregivers as well as other care-providers (see Table 2). Table 1 also confirms that, on average, this category is represented mostly by women (88\%). This category is as likely to report having children as the non-provider category. Therefore, at least the women in this category are as likely to be burdened by childcare responsibilities as the non-provider population. The sandwich caregivers spend the least time on paid work compared to other categories (6 min on an average day). It is magnitudes below the total average (190 min). This suggests that the 
'sandwich' caregivers are the least likely to work because of their doubled responsibilities in care for the elderly and children. They are more likely to report this daily lifestyle on a weekday, rather than a weekend. They are also significantly more likely to own the home that they live in compared to non-caregivers.

\section{Service Sector Worker Caregivers}

Although the 'worker' caregivers are less likely to have children than non-caregivers, the difference is not on a statistically significant level. They are, however, significantly more likely to spend more time on paid activities than non-caregivers, which is also evident in their tempograms in Appendix A. The tempograms also show that workers are also more likely to work the evening shifts.

Because of the peculiar daily patterns among this group and travelers (Group 5), we decided to analyse the categories by occupation. Table 3 summarises the occupations, in which the different categories of the care-providers report to be involved. The table shows that a higher percentage of Groups 1-3 are not in the workforce, whereas $98.2 \%$ of the 'worker' caregivers and $97 \%$ of the 'traveller' caregivers are in the labour market. The occupational distributions reveal that among the 'worker' caregivers, it is more common to take up jobs as sales representatives (24.38\%) and other service jobs (23.75\%). This is a typical demographic for the working poor in Japan. Thus, the 'worker' caregivers are mostly represented by the working poor employed in the service sector.

Table 3. Cross-Tabulation of Categories with Professions

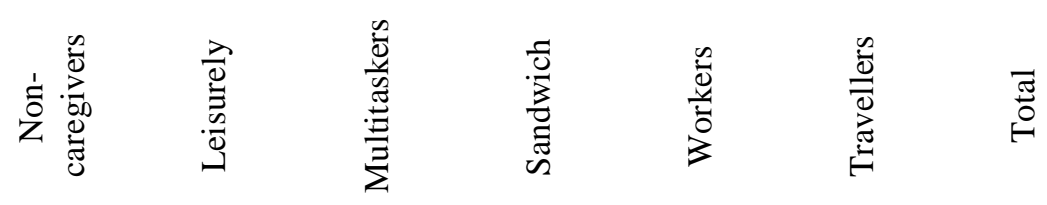

\begin{tabular}{lccccccc}
\hline Not in workforce & 41.211 & 56.048 & 77.408 & 72.163 & 1.250 & 3.008 & 41.317 \\
trades: technician & 1.807 & 0.756 & 0.832 & 0.355 & 1.250 & 1.598 & 1.786 \\
trades: instructor & 1.402 & 0.864 & 0.119 & 0.177 & 1.250 & 1.316 & 1.384 \\
trades: other trades occupation & 4.618 & 4.536 & 1.546 & 2.128 & 6.250 & 6.579 & 4.606 \\
managerial occupation & 1.587 & 1.512 & 1.308 & 0.355 & 1.250 & 3.383 & 1.593 \\
office worker & 10.487 & 8.099 & 4.162 & 5.674 & 6.875 & 14.474 & 10.439
\end{tabular}




\begin{tabular}{lccccccc} 
sales representative & 7.195 & 4.752 & 2.021 & 2.305 & 24.375 & 8.365 & 7.155 \\
services: care support service worker & 0.353 & 1.188 & 0.238 & 0.532 & 1.250 & 0.564 & 0.362 \\
services: insurance worker & 0.798 & 0.972 & 0.119 & 0.000 & 2.500 & 0.564 & 0.792 \\
services: other service worker & 5.598 & 3.672 & 2.021 & 3.901 & 23.750 & 7.237 & 5.589 \\
agriculture worker & 4.681 & 4.104 & 2.735 & 3.014 & 5.625 & 24.718 & 4.816 \\
transport worker & 1.875 & 1.296 & 0.832 & 0.000 & 3.750 & 1.974 & 1.859 \\
industry: worker & 0.023 & 0.000 & 0.000 & 0.000 & 0.000 & 0.000 & 0.023 \\
industry: construction worker & 13.031 & 9.503 & 3.567 & 4.965 & 10.000 & 16.729 & 12.941 \\
industry: blue collar worker & 3.189 & 0.972 & 2.021 & 2.482 & 4.375 & 5.545 & 3.184 \\
unclassifiable job & 2.145 & 1.728 & 1.070 & 1.950 & 6.250 & 3.947 & 2.154 \\
Total & 100.000 & 100.000 & 100.000 & 100.000 & 100.000 & 100.000 & 100.000 \\
\hline$N$ & 136596 & & & & & & \\
\hline
\end{tabular}

\section{Agriculture/Construction Traveler Caregivers}

Table 2 shows that the 'traveller' caregivers are significantly less likely to have children compared to non-caregivers. They are also more likely to spend time on paid work than non-caregivers. This category of caregivers is more likely to own their homes than non-caregivers as well as they are more likely to report these daily lifestyles on weekdays than on weekends. Table 3 further reveals that the traveller lifestyle is more common among agricultural workers (24.72\%) and construction workers $(16.73 \%)$, regardless of whether they are women or men. The tables for occupations broken down by gender reveal similar patterns as reported for the total sample. Thus, we also can refer to this category as the 'agriculture/construction travellers'.

\section{Conclusions}

Overall, our results show that the three categories of caregivers out of five, identified in the cluster analysis, do not participate commonly in paid work activities. Among the three, only the pattern for the 'leisurely' caregivers was typical on weekends, when the majority of the workforce was not at work. These results suggest that only one cluster among caregivers was indicative of weekend caregivers' lifestyle, and there are hardly any differences between women and men, who provide eldercare on weekends. The sandwich caregivers were the least likely to engage in paid work and the most likely to be out of work because childcare and concomitant housework activities burdened them. All caregivers faced harsher economic challenges than non-caregivers. The at-risk populations identified here were the sandwich caregivers and the working poor, both of which were more likely to be represented by women than men.

This is the first paper to address the daily lifestyles and similarities, as well as differences, between 
elder caregivers. The findings give us some hope in terms of gender equality, which is observed on weekends among some caregivers. On the other hand, our results are a cautionary tale that even in a country with progressive eldercare policies, the disadvantaged populations such as women and the working poor take on a harder hit.

The present findings, therefore, show that women are pushed disproportionately into the subservient positions and poverty as the consequence of the lack of time to involve in paid work, inability to secure higher-paying jobs due to increased care responsibilities, as well as due to other mechanisms working against women and the working poor who provide elder care in Japan. The present study shows that the revision of the long-term insurance system did not alleviate gender imbalance as it initially aimed to. More policy improvement would be needed to address the intersections of gender and poverty in elder care.

The future research could focus on the elder caregivers in other countries and in other welfare regimes to explore the consequences of eldercare on gender and economic equality.

\section{References}

Abbott, A. 1995. Sequence analysis: new methods for old ideas. Annual review of sociology, 21, 1, 93-113.

Abbott, A. and Tsay, A. 2000. Sequence analysis and optimal matching methods in sociology: Review and prospect. Sociological methods \& research, 29, 1, 3-33.

Aoun, S., Deas, K., Toye, C., Ewing, G., Grande, G. and Stajduhar, K. 2015. Supporting family caregivers to identify their own needs in end-of-life care: Qualitative findings from a stepped wedge cluster trial. Palliative medicine, 29, 6, 508-517.

Ato, M. 阿., 誠) and Tsuya, N.津., 典子). 2018. 少子高齢社会の諸相。. In 津谷，典., 阿藤，誠., 西岡，八. and 福田, 亘. (eds), 少子高齢時代の女性と家族. 慶應義塾大学出版会, 東京, 1-55.

Bianchi, S.M., Milkie, M.A., Sayer, L.C. and Robinson, J.P. 2000. Is anyone doing the housework? Trends in the gender division of household. Social Forces, 79, 191-228.

Bianchi, S.M., Robinson, J.P. and Milkie, M.A. 2006. Changing Rhythms of American Family Life. Russell Sage Foundation, New York, NY.

Bittman, M., England, P., Sayer, L., Folbre, N. and Matheson, G. 2003. When Does Gender Trump Money? Bargaining and Time in Household Work. American Journal of Sociology, 109, 1, 186-214.

Boltz, M., Chippendale, T., Resnick, B. and Galvin, J.E. 2015. Anxiety in family caregivers of hospitalized persons with dementia: contributing factors and responses. Alzheimer disease and associated disorders, 29, 3, 236.

Bookman, A. and Kimbrel, D. 2011. Families and elder care in the twenty-first century. The Future of Children, 21, 2, 117-140.

Cancian, F.M. and Oliker, S.J. 2000. Caring and gender. Rowman \& Littlefield. 
Couch, K.A., Daly, M.C. and Wolf, D.A. 1999. Time? Money? Both? The allocation of resources to older parents. Demography, 36, 2, 219-232.

England, P. 2005. Gender inequality in labor markets: The role of motherhood and segregation. Social Politics, 12, 264-288.

Folbre, N. 2012. For Love and Money: Care Provision in the United States. . Russell Sage Foundation., New York.

Fukuda, N.福., 亘孝). 2018. 親子の支援関係の特徵と規定要因：SANDWICH GENERATIONを中心にして。. In 津谷, 典., 阿藤, 誠., 西岡, 八. and 福田, 亘. (eds), 少子高齢時代の女性と家族. 慶應義塾大学出 版会, 東京, 237-259.

Gerstel, N. 2000. The third shift: Gender and care work outside the home. Qualitative Sociology, 23, 4, 467-483.

Grapsa, E. and Posel, D. 2016. Sequencing the real time of the elderly: Evidence from South Africa. Demographic Research, 35, 711-744.

Grigoryeva, A. 2017. Own gender, sibling's gender, parent's gender: The division of elderly parent care among adult children. American Sociological Review, 82, 1, 116-146.

HelpAge International. 2014. Global AgeWatch Index 2015. In.

Henretta, J.C., Grundy, E. and Harris, S. 2001. Socioeconomic differences in having living parents and children: A USBritish comparison of middle-aged women. Journal of Marriage and Family, 63, 3, 852-867.

Henz, U. 2010. Parent care as unpaid family labor: How do spouses share? Journal of Marriage and Family, 72, 1, 148-164.

Hertog, E., Kan, M.Y., Shirakawa, K. and Chiba, R. 2018. Do Better-Educated Couples Share Domestic Work More Equitably in Japan? It Depends on the Day of the Week.

Hook, J.L. 2017. Women's Housework: New Tests of Time and Money. Journal of Marriage and Family, 79, 1, 179198.

Hou, R.J., Wong, S.Y.-S., Yip, B.H.-K., Hung, A.T., Lo, H.H.-M., Chan, P.H., Lo, C.S., Kwok, T.C.-Y., Tang, W.K. and Mak, W.W. 2014. The effects of mindfulness-based stress reduction program on the mental health of family caregivers: a randomized controlled trial. Psychotherapy and psychosomatics, 83, 1, 45-53.

Kolpashnikova, K. 2018. American Househusbands: New Time Use Evidence of Gender Display, 2003-2016. Social Indicators Research, 140, 3, 1259-1277.

Levitsky, S.R. 2014. Caring for our own: Why there is no political demand for new American social welfare rights. Oxford University Press, USA.

Moen, P., Robison, J. and Fields, V. 1994. Women's work and caregiving roles: A life course approach. Journal of Gerontology, 49, 4, S176-S186.

Morikawa, M.森., 美絵). 2018. 日本の介護政策における「介護の社会科」の展開。. In 須田, 木., 平岡, 公. and 森川, 美. (eds), 東アジアの高齢者ケア. 東信堂, 東京, 280-305.

Nichols, L.S. and Junk, V.W. 1997. The sandwich generation: Dependency, proximity, and task assistance needs of parents. Journal of Family and Economic Issues, 18, 3, 299-326.

Ruppanner, L. and Treas, J. 2015. Working weekends: Changing European time regimes and gender inequality in 
household labor. Journal of Family Issues, 36, 13, 1782-1809.

Sankoff, D. and Kruskal, J.B. 1983. Time Warps, String Edits, and Macromolecules: The Theory and Practice of Sequence Comparison. Addison-Wesley, Reading, MA.

Silverstein, M. and Giarrusso, R. 2010. Aging and family life: A decade review. Journal of marriage and family, 72, 5, 1039-1058.

Statistics Bureau. 2016. Survey on Time Use and Leisure Activities. In.

Suh, J. 2016. Measuring the "sandwich": Care for children and adults in the American Time Use Survey 2003-2012. Journal of family and economic issues, 37, 2, 197-211.

Szinovacz, M.E. and Davey, A. 2008. The division of parent care between spouses. Ageing \& Society, 28, 4, 571-597.

Tay, K.C.P., Seow, C.C.D., Xiao, C., Lee, H.M.J., Chiu, H.F. and Chan, S.W.-C. 2016. Structured interviews examining the burden, coping, self-efficacy, and quality of life among family caregivers of persons with dementia in Singapore. Dementia, 15, 2, 204-220.

Weisser, F.B., Bristowe, K. and Jackson, D. 2015. Experiences of burden, needs, rewards and resilience in family caregivers of people living with motor neurone disease/amyotrophic lateral sclerosis: a secondary thematic analysis of qualitative interviews. Palliative medicine, 29, 8, 737-745.

Wolf, D.A. and Soldo, B.J. 1994. Married women's allocation of time to employment and care of elderly parents. Journal of Human resources, 1259-1276.

Yamashita, J. and Soma, N. 2015. The double responsibilities of care in Japan: emerging new social risks for women providing both childcare and care for the elderly. In New Life Courses, Social Risks and Social Policy in East Asia. Routledge, 113-129.

Zuba, M. and Schneider, U. 2013. What helps working informal caregivers? The role of workplace characteristics in balancing work and adult-care responsibilities. Journal of family and economic issues, 34, 4, 460-469. 


\section{Appendix A. Group Tempograms}

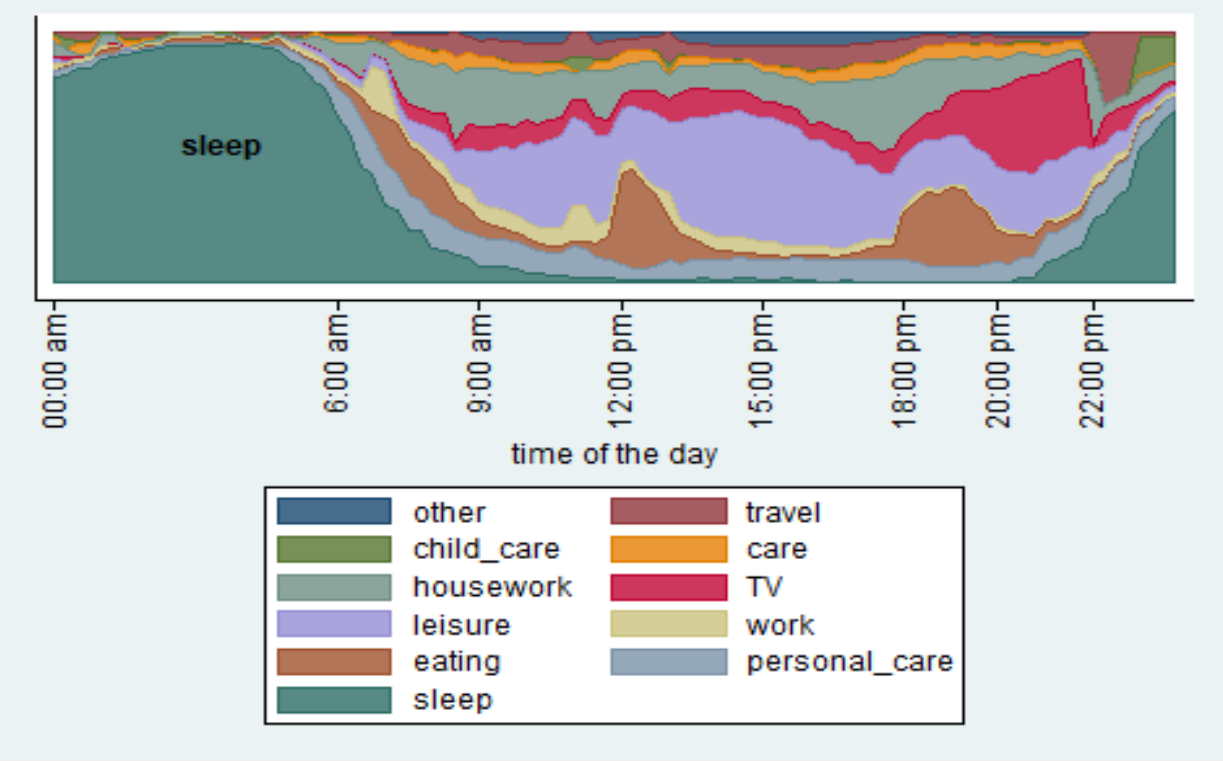

Figure A1 Leisurely Caregivers Tempogram

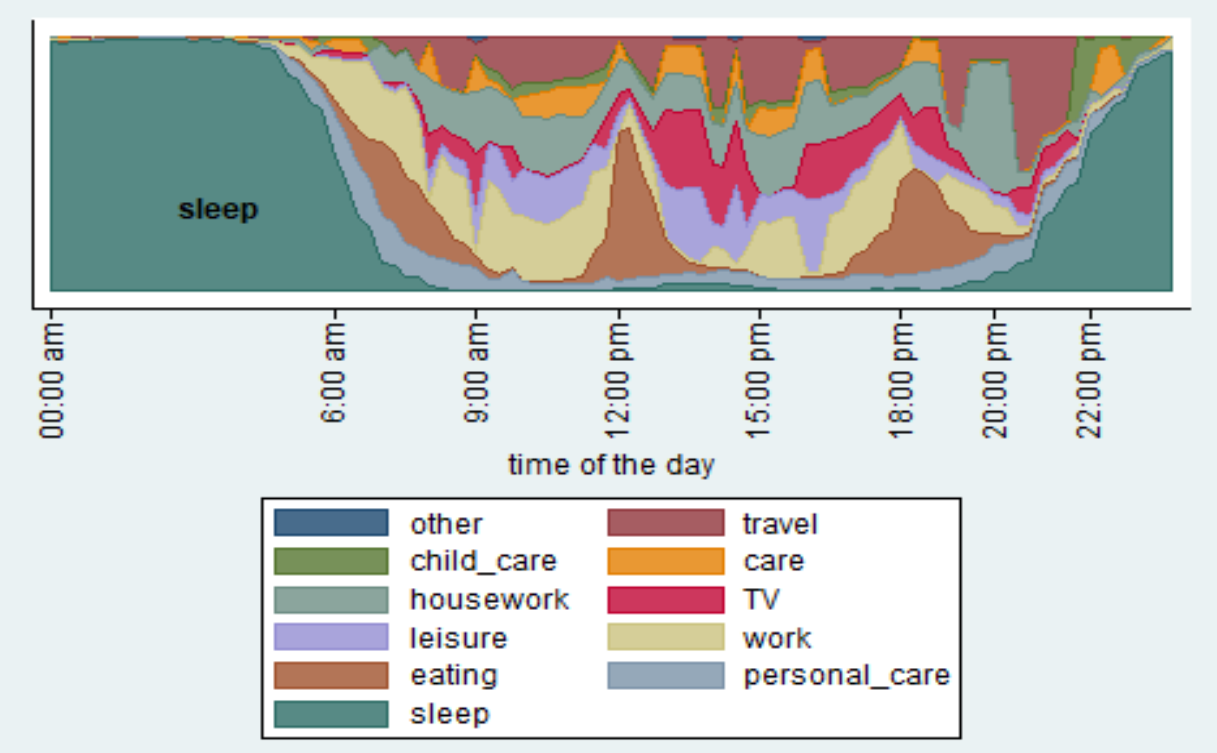

Figure A2 Multitaskers Tempogram 


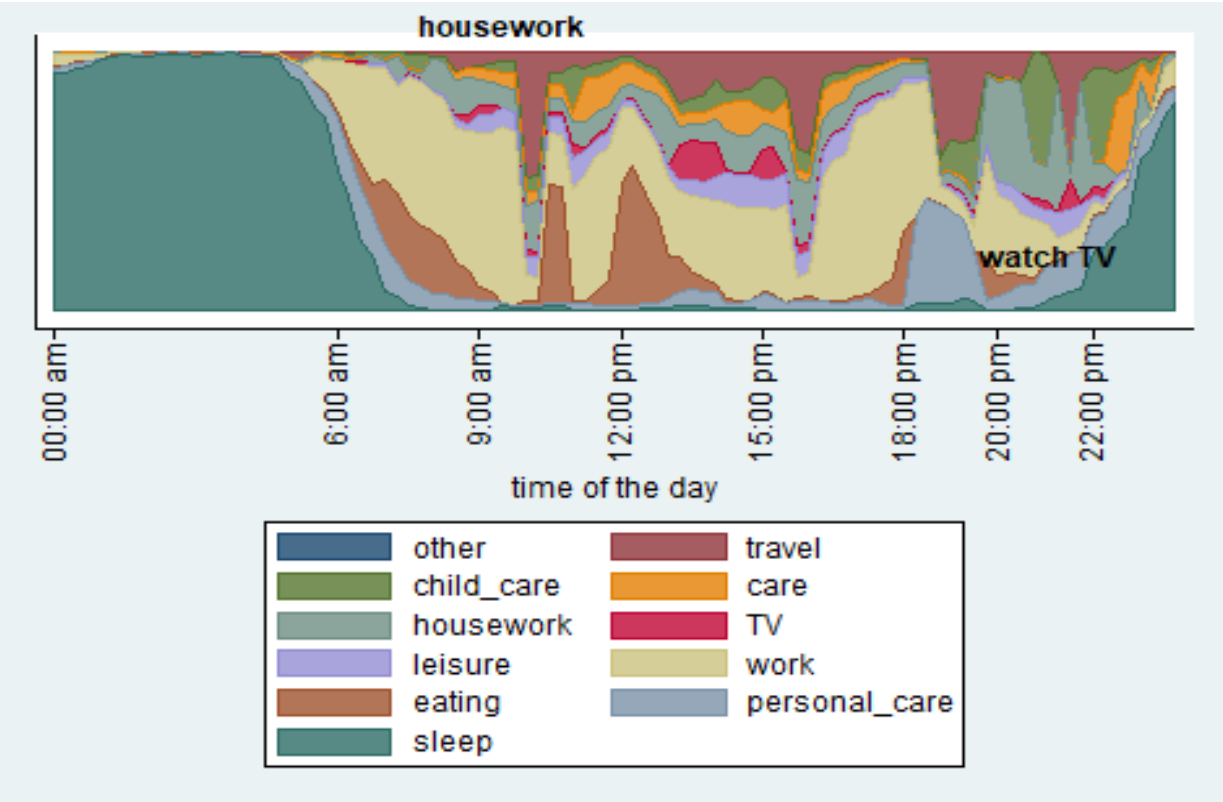

Figure A3 Sandwich Caregivers Tempogram

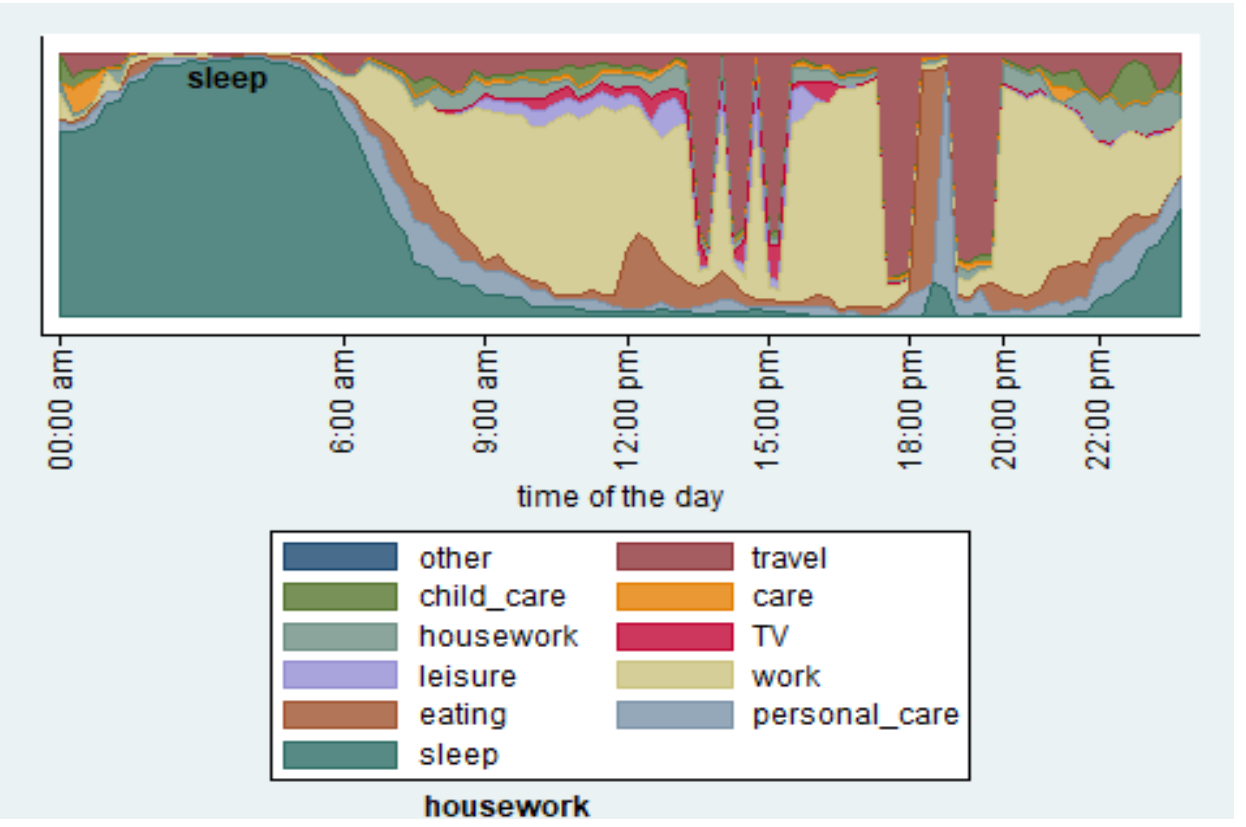

Figure A4 Working Poor Tempogram 


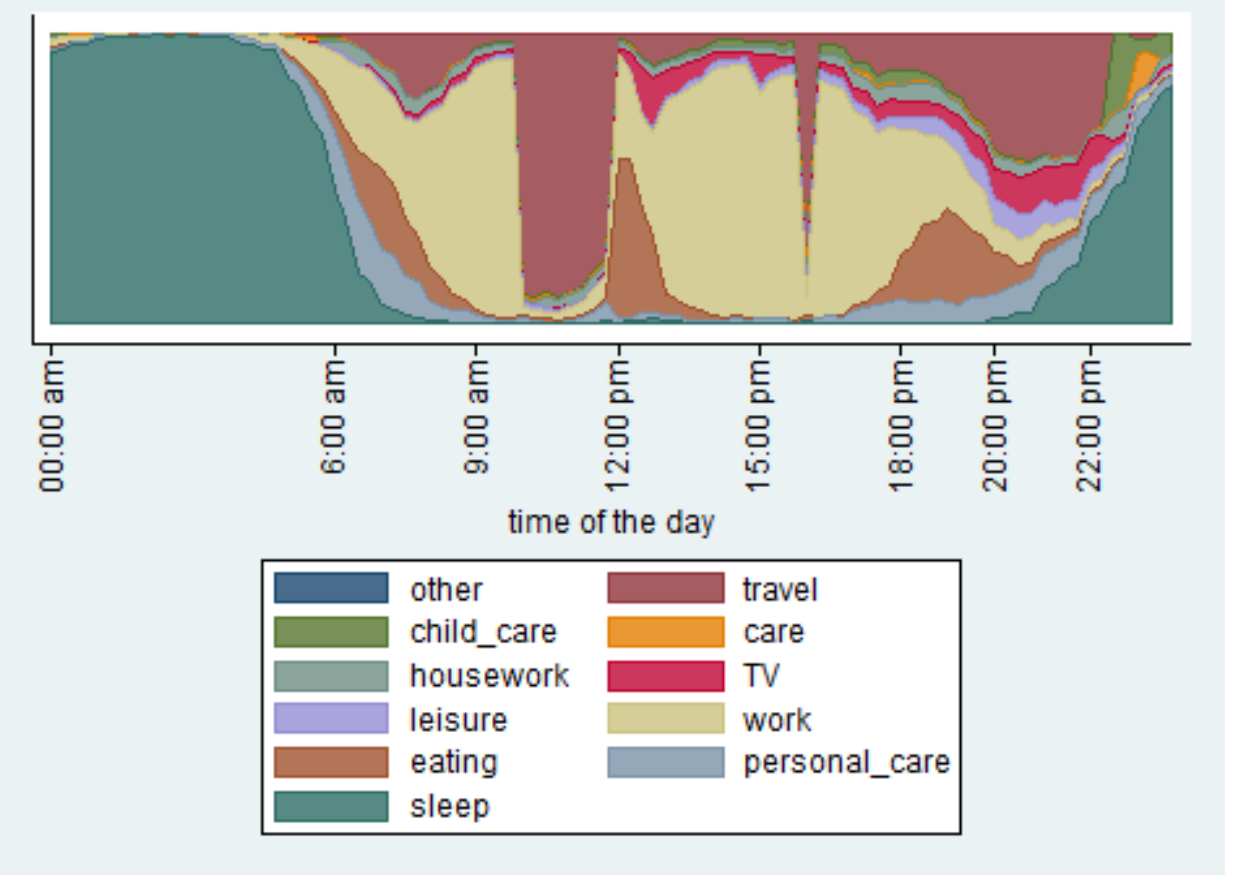

Figure A5 Travelers Tempogram 